\title{
The Relationship between Stress Coping Strategies and Social Skills with Aggression in Deaf Female Students
}

\author{
Bita Shalani (MSc) ${ }^{1}$, Faride Alimoradi (MSc) ${ }^{2, *}$, Saeid Sadeghi (MSc) ${ }^{3}$ \\ ${ }^{I}$ PhD Students of Psychology, Department of Psychology, Faculty of Human Science, Tarbiat Modares University, Tehran, \\ Iran \\ ${ }^{2}$ MSc of Psychology, Department of Psychology, Faculty of Social Science, Razi University, Kermanshah, Iran \\ ${ }^{3}$ PhD Candidate of Clinical psychology, Department of Clinical and Health Psychology, Faculty of Psychology and \\ Education, Shahid Beheshti University, Tehran, Iran
}

* Corresponding Author: Faride Alimoradi, Department of Psychology, Faculty of Social Science, Razi University, Kermanshah, Iran. Email: faridealimoradi.zendegi@gmail.com

\begin{tabular}{|c|c|}
\hline & Abstract \\
\hline $\begin{array}{l}\text { Received: } 19 / 01 / 2016 \\
\text { Accepted: } 12 / 04 / 2017\end{array}$ & \multirow[b]{2}{*}{$\begin{array}{l}\text { Background and Objective: Deafness is the most common human } \\
\text { sensory impairment. Students with hearing impairment have more behavior } \\
\text { problems in terms of emotion, education and communication with others. } \\
\text { The purpose of this study was to investigate the relationship between stress } \\
\text { coping strategies and social skills with aggression in deaf female students. } \\
\text { Materials and Methods: In this correlative-descriptive study, } 50 \text { deaf } \\
\text { female students with } 12 \text { to } 20 \text { years old were selected by census sampling } \\
\text { method from all exceptional schools in Kermanshah city in 2014-15 } \\
\text { academic years. Data is collected with Buss and Perry Aggression } \\
\text { Questionnaire (BPAQ), The Teenage Inventory of Social Skills (TISS) and } \\
\text { Coping Inventory for Stressful Situation (CISS-21). The collected data } \\
\text { were analyzed in the SPSS software (IBM SPSS Version } 21 \text { ) using the } \\
\text { pearson correlation coefficient and regression analysis. } \\
\text { Results: Findings showed that there wasn't a significant relationship } \\
\text { between problem-oriented coping style and aggression ( } \mathrm{p}=0 / 115 \text { ), but there } \\
\text { was a significant relationship between emotionally-oriented (p=0/19) and } \\
\text { avoidance-oriented style ( } \mathrm{p}=0 / 12 \text { ) with aggression. There was a significant } \\
\text { negative relationship between social skills and total aggression score } \\
\text { (p=0/46), physical aggression ( }=0 / 41 \text { ), verbal aggression ( }=0 / 28 \text { ), angry } \\
\text { (p=0/32) and hostility ( } \mathrm{p}=0 / 19 \text { ). Also social skills ( } \mathrm{p}=0 / 23 \text { ), emotionally- } \\
\text { oriented ( } \mathrm{p}=0 / 12 \text { ) and avoidance-oriented style ( } \mathrm{p}=0 / 31 \text { ) can predict } \\
\text { aggression. } \\
\text { Conclusion: Regarding to relationship between stress coping strategies and } \\
\text { social skills with aggression, we can reduced disturbances, stress } \\
\text { and consequently aggressions, by training individuals in coping with } \\
\text { psychological problems and stress. , and provided effective help in mental } \\
\text { health of deaf students. Therefore it is necessary to consider the education } \\
\text { programs in social skills by educators in exceptional schools. }\end{array}$} \\
\hline $\begin{array}{l}\text { How to Cite this Article: } \\
\text { Shalani B, Alimoradi F, Sadeghi } \\
\text { S. The Relationship between } \\
\text { Stress Coping Strategies and } \\
\text { Social Skills with Aggression } \\
\text { in Deaf Female Students. } \\
\text { Pajouhan Scientific Journal. } \\
2018 ; \quad 16(2): \quad 11-18 . \quad \text { DOI: } \\
\begin{array}{l}\text { 10.21859/psj.16.2.11 }\end{array}\end{array}$ & \\
\hline & Keywords: Aggression; Coping Strategies; Deafness; Social Skills; Students \\
\hline
\end{tabular}

Copyright (C) 2018 Pajouhan Scientific Journal. This is an open-access article distributed under the terms of the Creative Commons Attribution-NonCommercial 4.0 International License (http://creativecommons.org/licenses/by-nc/4.0/) which permits copy and redistribute the material just in noncommercial usages, provided the original work is properly cite. 


\section{رابطه سبكهاى مقابله با استرس و مهارتهاى اجتماعى با يرخاشكرى در دانش آموزان}

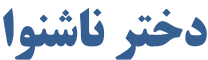

بيتا شلانى'، فريده عليمرادى r'، سعيد صادقى

' دانشجوى دكترى تخصصى روانشناسى، گروه روانشناسى، دانشكده علوم انسانى، دانشًاه تربيت مدرس، تهران، ايران

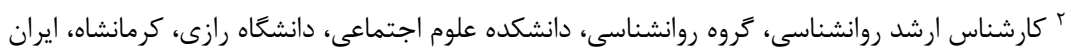

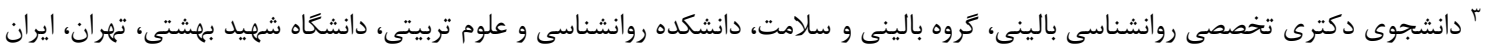
* نويسنده مسئول: فريده عليمر ادى، گروه روانشناسى، دانشكده علوم اجتماعى، دانشخاه رازى، كرمانشاه، ايران.

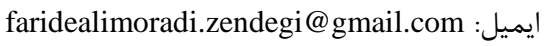

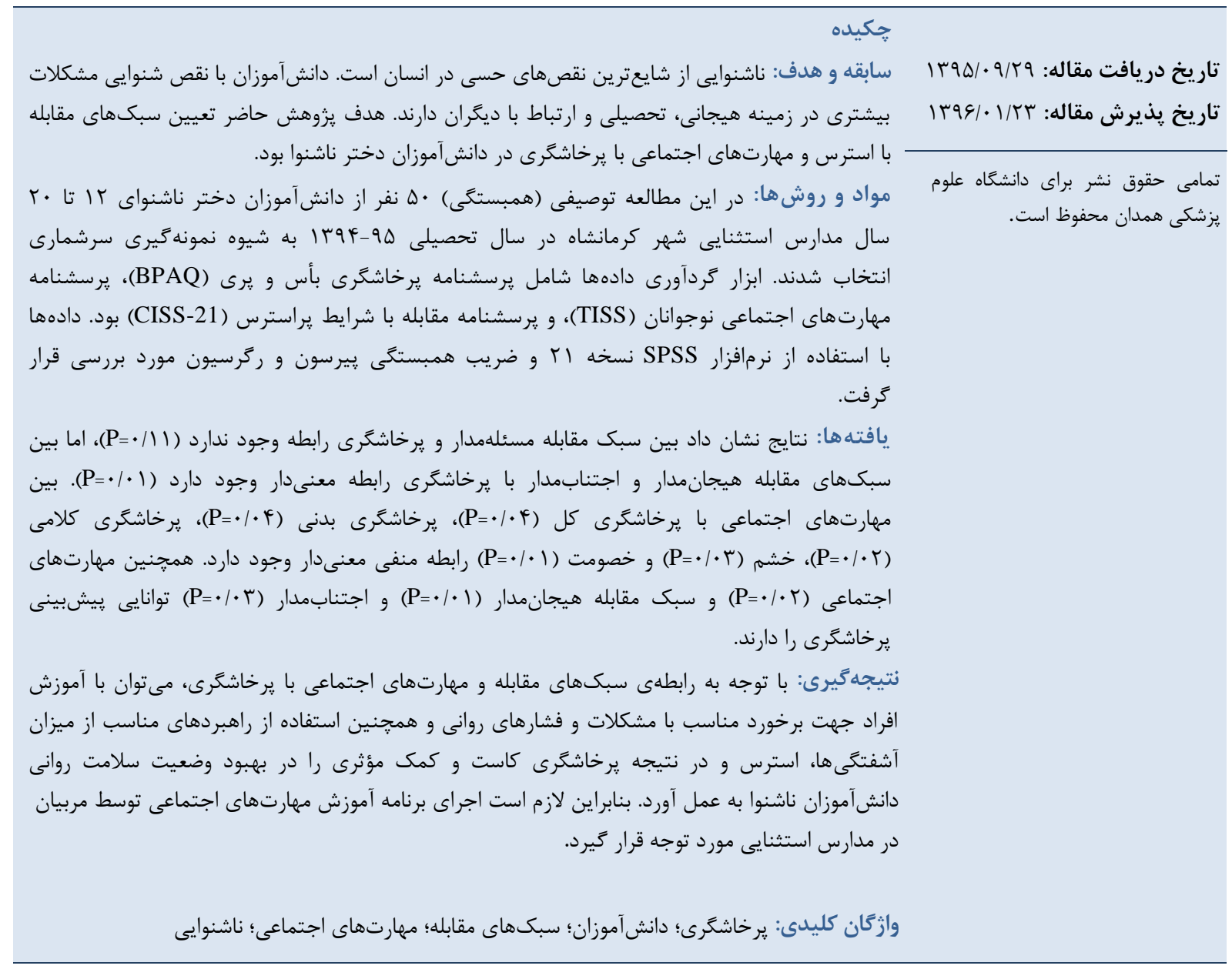

مقدمه - -

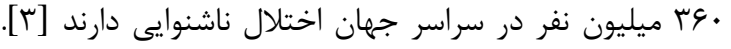

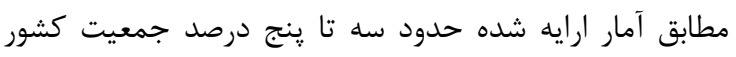

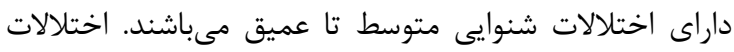

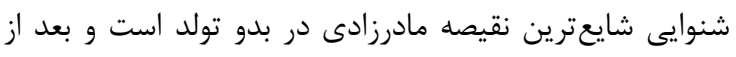

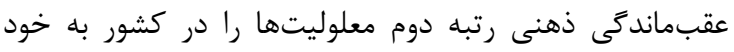

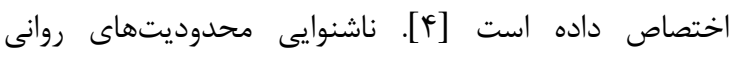

نقص شنوايى از شايعترين نقصهاى حسى در انسان است.

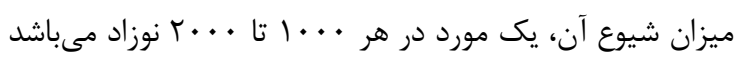

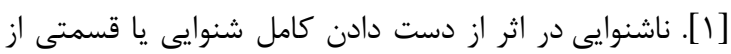

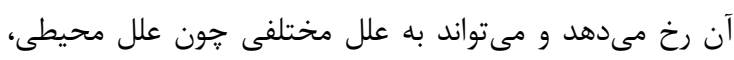

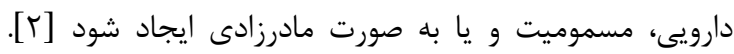

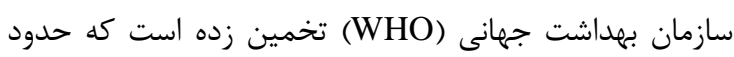


كنترل نشانههاى فشار متمركز مىشود [Yץ]]، در مقابله اجتنابى

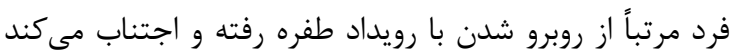

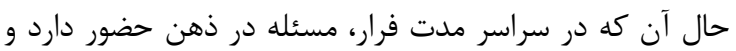

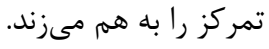

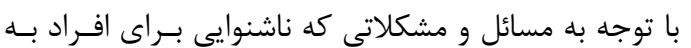

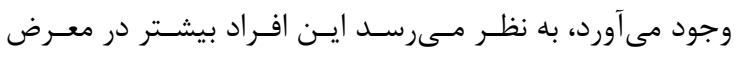

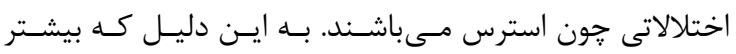

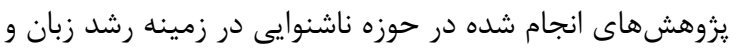

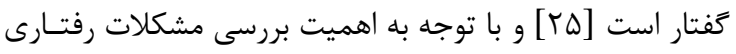

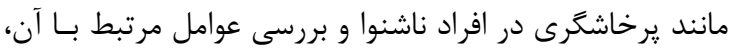

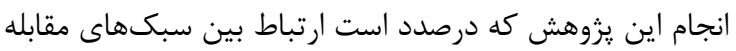

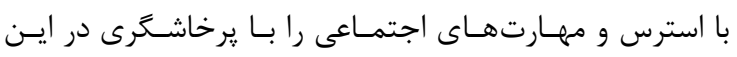
دانشآموزان بررسى كند، ضرورى مىنمايد.

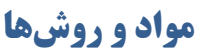

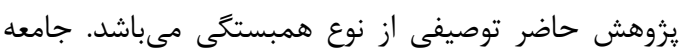

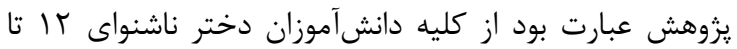

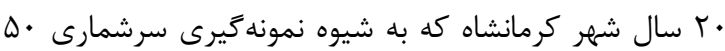

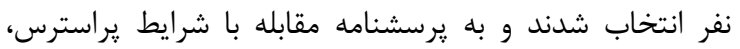

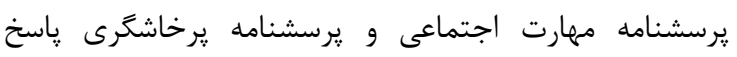

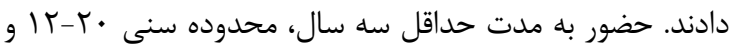

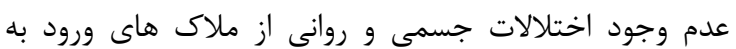

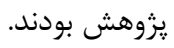

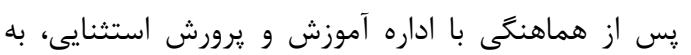
تمامى مدارس استثنايى دخترانه شهر كرمانشاه مراجعه شاره

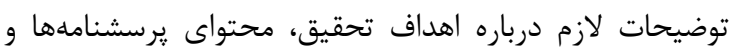

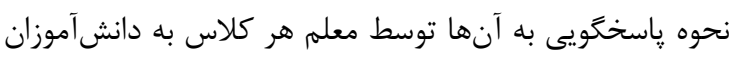

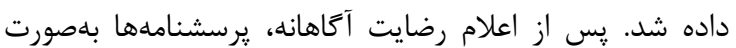
انفرادى تكميل شدند. ابزار يزوهش حاضر شامل سه برسشنامه بود: (1) يرسشنامه

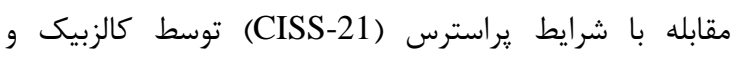

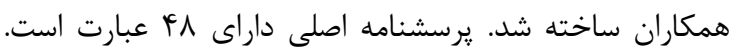

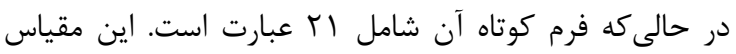

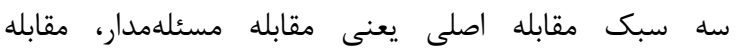

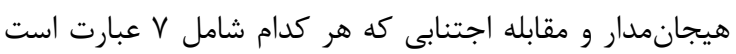

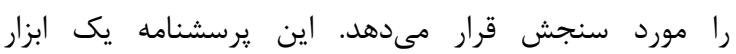

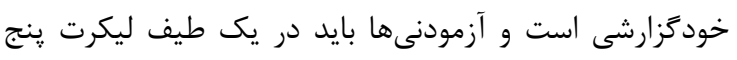

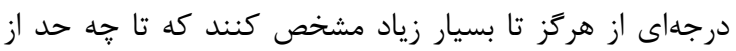

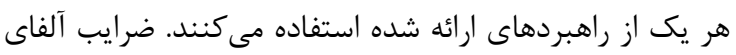

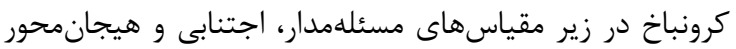

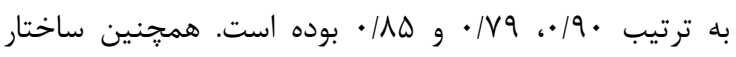

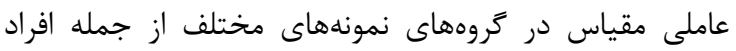

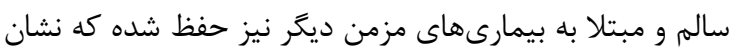

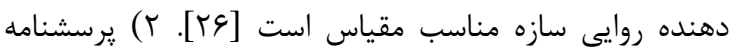

|جتماعى بسيارى را به دنبال دارد كه از آن جمله مىتوان

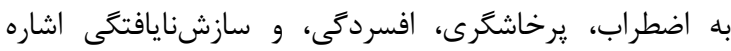
كرد [0] از مواردى كه دانشآموزان ناشنوا را دجار مشكل مى كند،

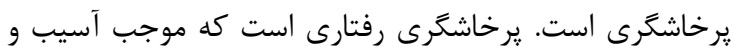

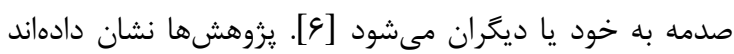

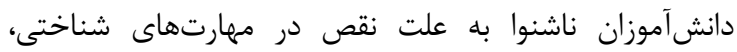

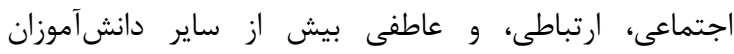

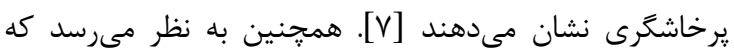

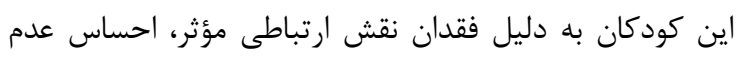

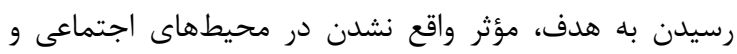

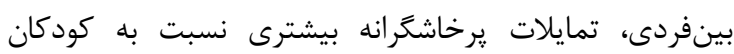

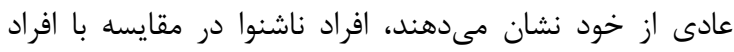

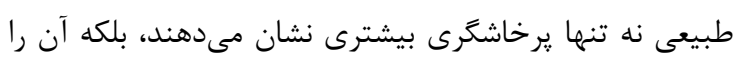

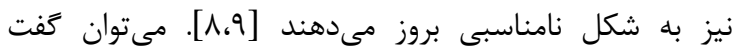

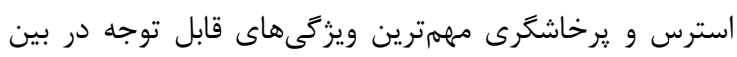

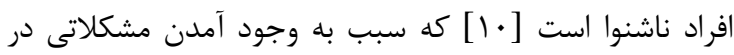

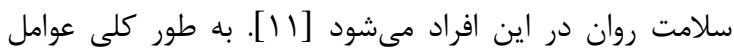

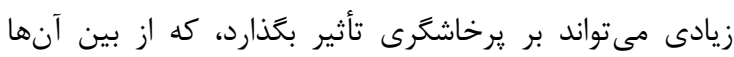

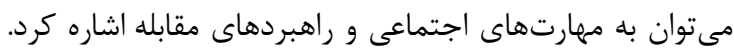

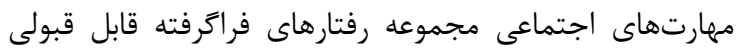

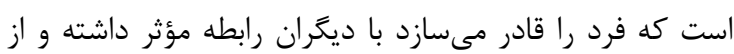

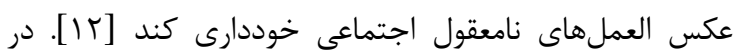

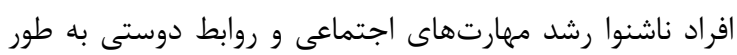

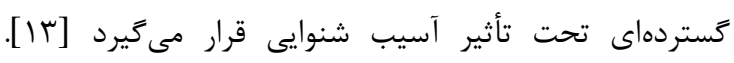

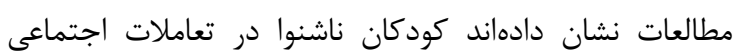

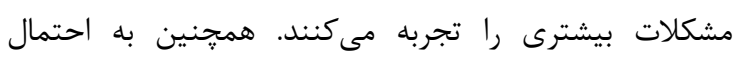

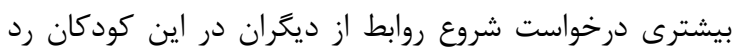

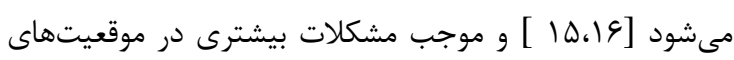

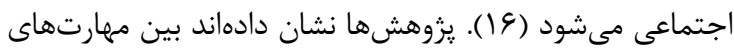

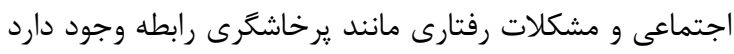

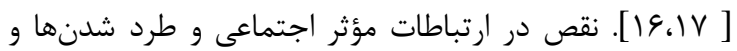

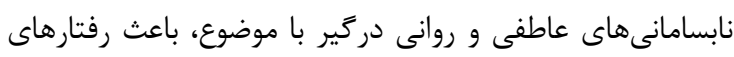

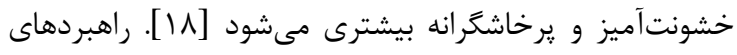

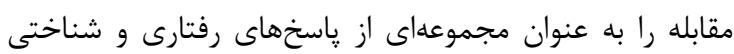

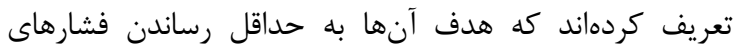

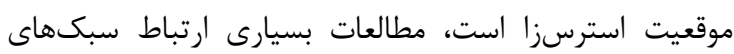

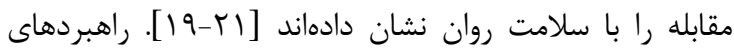

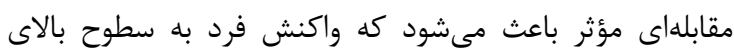

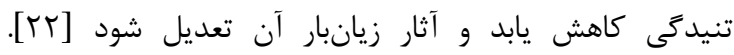

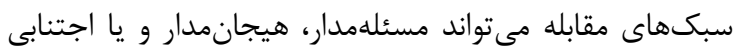

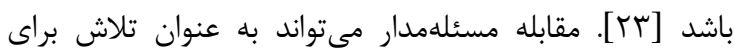

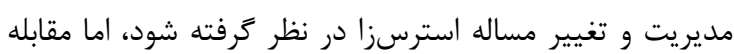
هيجانمدار تلاش براى كم كردن استرس هيجانى است و روى 


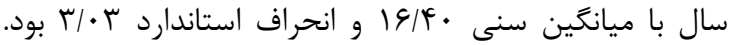

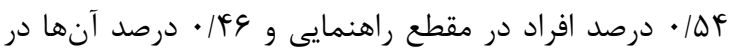

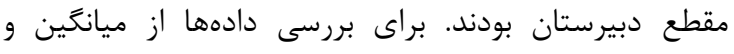

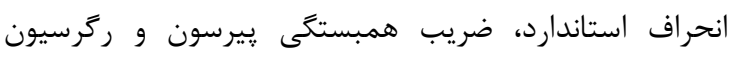

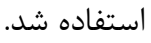

نتايج بررسى ميانگينها (جدول ( ) نشان مى دهد ميانگين

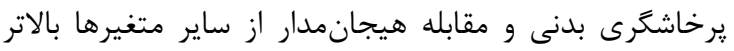

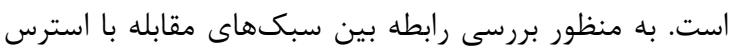

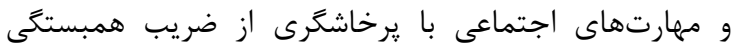

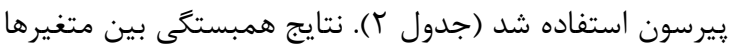

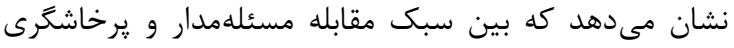

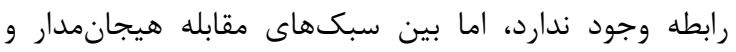

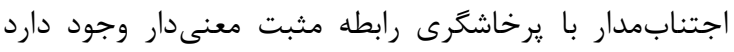

$(\mathrm{P}<\cdot / \cdot \Delta)$

جدول ا: ميانگَين و انحراف استاندارد متغيرهاى يزوهش

\begin{tabular}{|c|c|c|}
\hline انحراف استاندارد & ميانتين & \\
\hline TI/D & $I T / T F$ & يرخاشگرى بدنى \\
\hline $9 \vee / \%$ & $\Delta N / I r$ & يرخاشگرى كلامى \\
\hline TN/F & $r \cdot|r|$ & خشم \\
\hline N/9 & $\Delta G / T T$ & خصومت \\
\hline GV.D & $F T / T I$ & مقابله مسئلهمدار \\
\hline rI. & $V \cdot / T r$ & مقابله هيجانمدار \\
\hline VV.D & $99|\pi|$ & مقابله اجتنابمدار \\
\hline 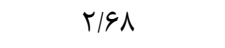 & $1 . / 9 r$ & مهارتهاى اجتماعى \\
\hline
\end{tabular}

همجنين نتايج نشان مىدهد كه بين خردمهقياسهاى يرخاشكرى مانند يرخاشكرى كلامى و خصومت بإِ سبكى مقابله

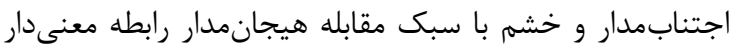

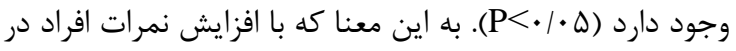

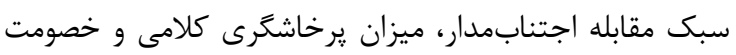

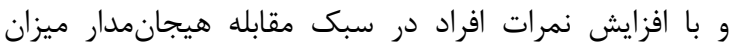

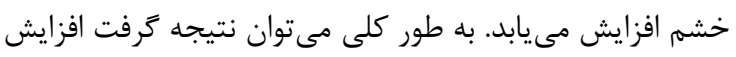

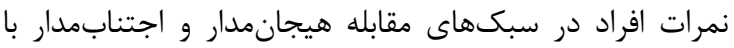

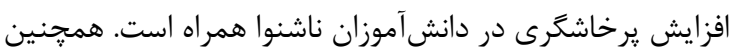

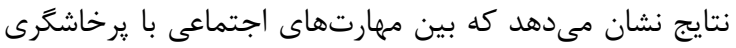

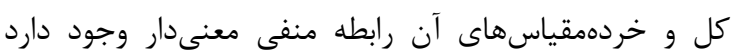

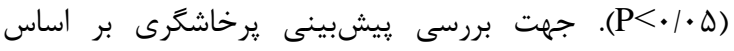

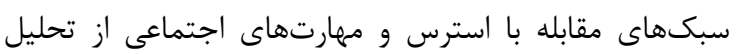

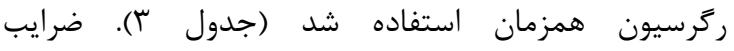

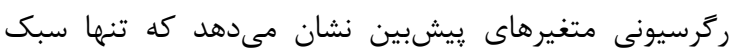

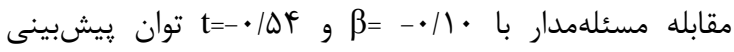

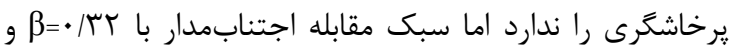

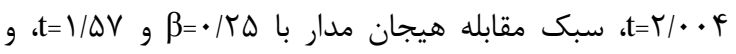

مهارتهاى اجتماعى نوجوانان (TISS): اين يرسشنامه توسط

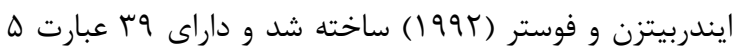

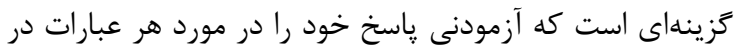

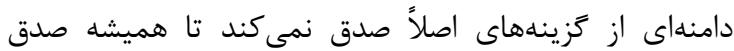

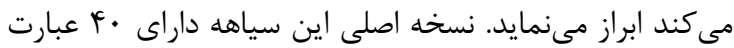

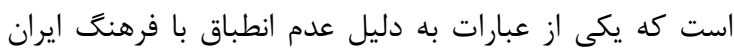

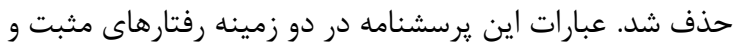

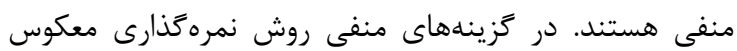

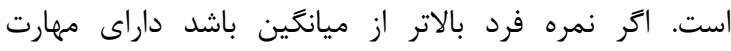

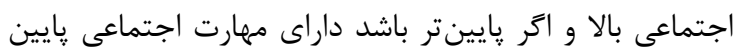

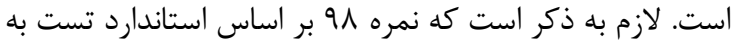

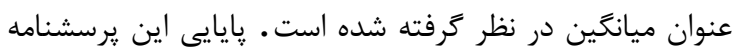

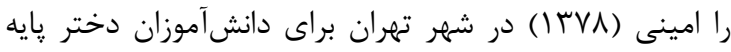

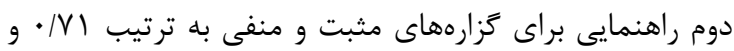

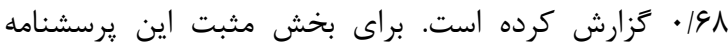

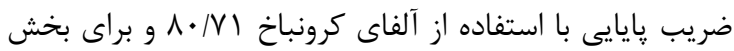

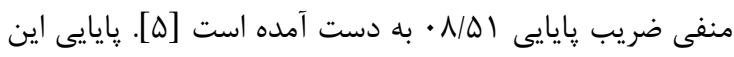

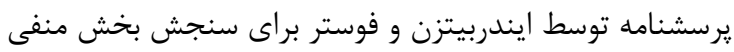

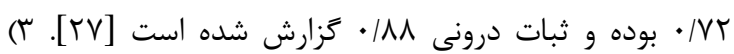

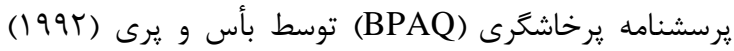

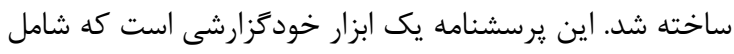

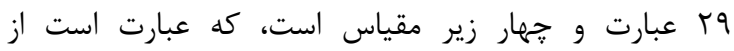

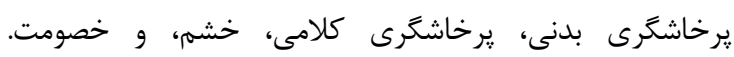

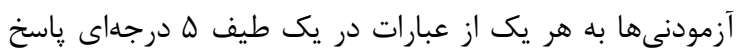

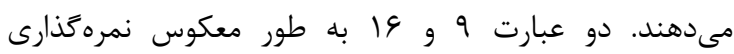

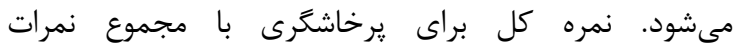

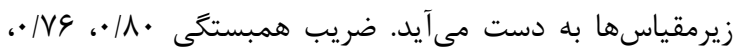

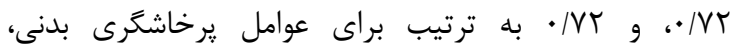

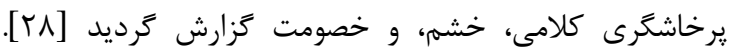

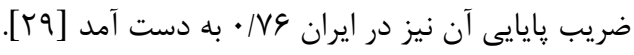

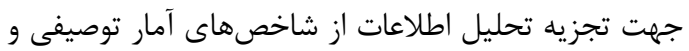

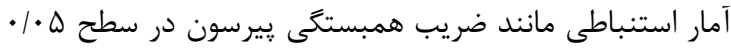
و ركرسيون همزمان به وسيله نرم افزار SPSS

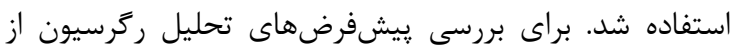

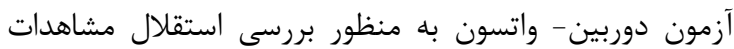

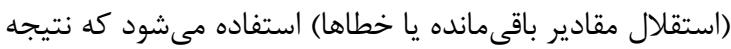

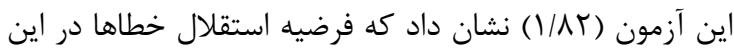

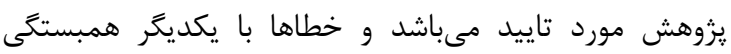

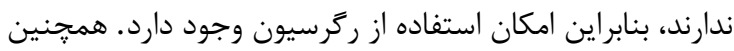

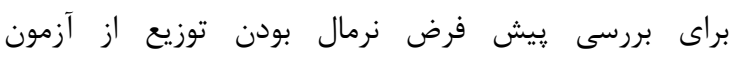
كولموكروف- اسميرنوف استفاده شد.

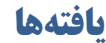

محدودهى سنى افراد شركت كننده در يزوهش r ا تا 
جدول r: همبستگى بين سبك هاى مقابله با استرس، مهارتهاى اجتماعى و يرخاشكرى

\begin{tabular}{|c|c|c|c|c|c|}
\hline مهارتهاى اجتماعى & مقابله اجتنابمدار & مقابله هيجانمدار & مقابله مسئلهمدار & & متغير ها \\
\hline${ }^{*}-\cdot \cdot 1 \cdot 1$ & $\cdot|r|$ & $\cdot / 4$ & $\cdot / T t$ & همبستگگ پيرسون & \multirow{2}{*}{ يرخاشكرى بدنى } \\
\hline$\cdot / \cdot t$ &.$/ 14$ & 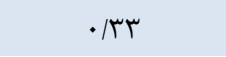 & .111 & معنى دارى & \\
\hline${ }^{*} \cdot \cdot / T r$ & $\cdot / 4 V$ & $\cdot|r|$ & $\cdot / 1 r$ & همبستخى پيرسون & \multirow{2}{*}{ يرخاشگرى كلامى } \\
\hline$\cdot / \cdot Y \Lambda$ & $\cdot / \cdot \Delta$ & $\cdot / 1 r$ & $\cdot / 49$ & معنى دارى & \\
\hline${ }^{*} \cdot \cdot / 1 \mathrm{~F}$ & $\cdot / K 4$ & ${ }^{*} \cdot 1 / 79$ & $\cdot / T F$ & همبستگى پِيرسون & \multirow{2}{*}{ خشم } \\
\hline$\cdot / \cdot r$ & $.1 \cdot 9$ & $\cdot / \cdot r$ & $\cdot / \cdot V$ & معنى دارى & \\
\hline${ }^{*} \cdot \cdot / 49$ & ${ }^{*} \cdot / 4 \Lambda$ & $\cdot / K \Delta$ & $\cdot 1 \cdot 1$ & همبستخى پِيرسون & \multirow{2}{*}{ خصومت } \\
\hline$\cdot 1 \cdot 1$ & $\cdot / \cdot r$ & $\cdot 1 \cdot 9$ & $\cdot / 1 \Delta$ & معنى دارى & \\
\hline${ }^{*} \cdot \cdot / T$ & ${ }^{*} \cdot / \pi \Delta$ & ${ }^{*} \cdot \pi$ & $\cdot / t r$ & همبستخى بيرسون & \multirow{2}{*}{ ل } \\
\hline$\cdot 1 \cdot \mathrm{F}^{\mathrm{f}}$ & $.1 \cdot 1$ & $\cdot 1 \cdot 1$ & $\cdot 111$ & معنى دارى & \\
\hline
\end{tabular}

جدول س: نتايج تحليل ركرسيون همزمان براى بيشبينى يرخاشكَى بر اساس سبكهاى مقابله با استرس و مهارتهاى اجتماعى

\begin{tabular}{|c|c|c|c|c|c|c|c|c|}
\hline $\mathbf{R}^{2}$ & $\mathbf{R}$ & $\mathbf{F}$ & $\mathbf{P}$ & $\mathbf{T}$ & $\beta$ & Std & B & متغير بيش بين \\
\hline & & & $\cdot \mid \Delta \Lambda$ & $-\cdot \mid Q F$ & $-\cdot / 1$ & $\cdot 10$ & $-\cdot / T V$ & مقابله مسئلهمدار \\
\hline & & & $\cdot 1 \cdot 1$ & $1 / \Delta V$ & $\cdot / r \Delta$ &.$/ 1 f$ & $\cdot \mid q 4$ & مقابله هيجان مدار \\
\hline & & &.$/ \cdot r$ & $r / \cdots r$ & . & $\cdot / f$ & $\cdot 1 \mathrm{~A}$ & مقابله اجتنابمدار \\
\hline & & & $\cdot 1 \cdot r$ & $-1 / V$ &.$- / 1 T$ & $\cdot$ /VG & $-\cdot / 1 T$ & مهارتهاى اجتماعى \\
\hline$\cdot / 11$ & מאוא & $r / 4 q$ & & & & & & يرخاشخرى \\
\hline
\end{tabular}

B

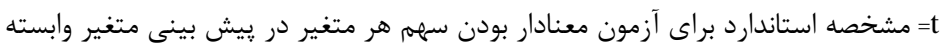

مى كنند. تنگَستانىزاده، احمدى و قريشىراد [YV] نيز در

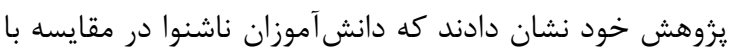

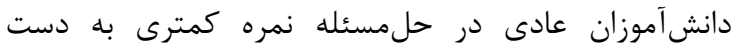
آوردند. - مافن يافته ديخر يزوهش حاضر نشان داد بين سبكهاى مقابله

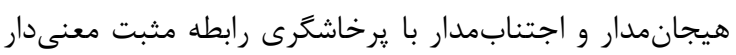

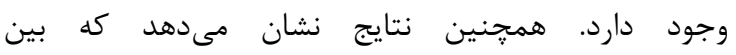

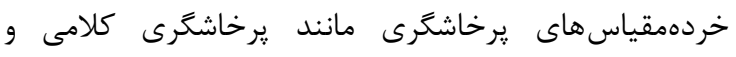

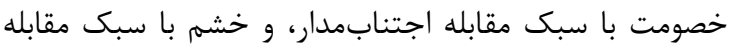

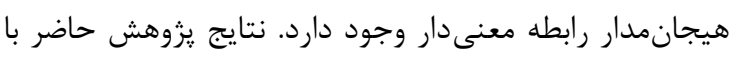

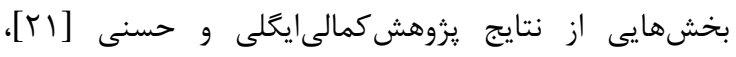

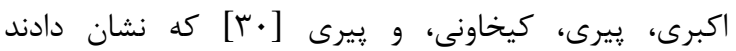

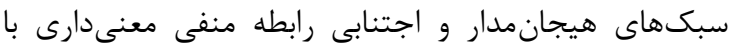

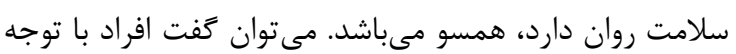

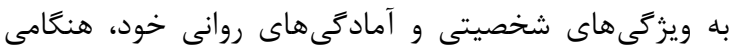

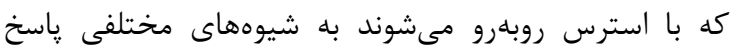

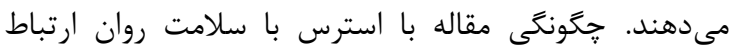

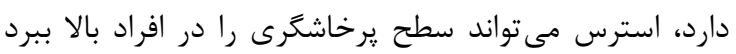

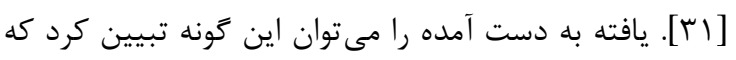

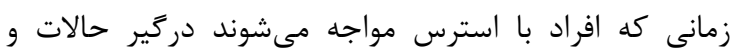

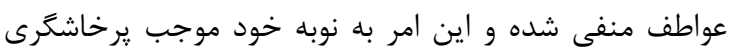
در افراد مىشود. در اين شرايط اگر افراد از سبكهاى مونى مقابله

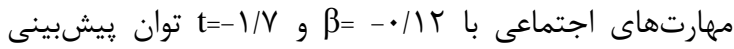
يرخاشخرى را دارند.

\section{بحث}

يزوهش حاضر با هدف تعيين رابطه سبكهاى مقابله با

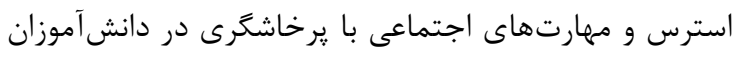

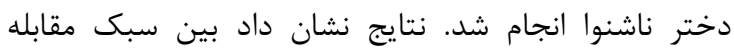

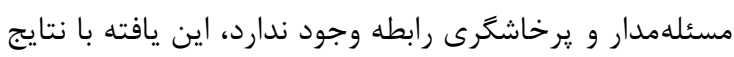

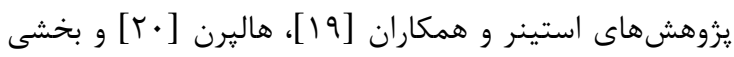

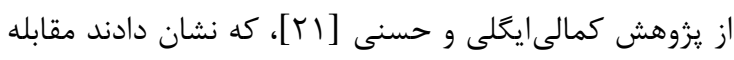

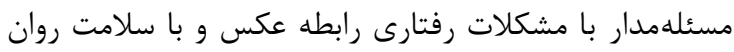

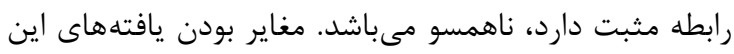

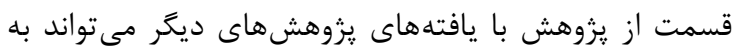

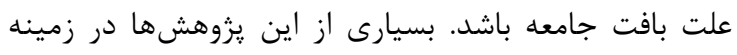

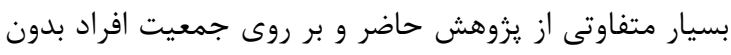

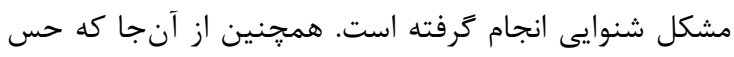

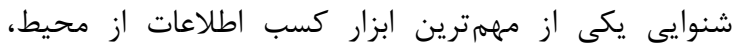

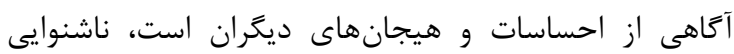

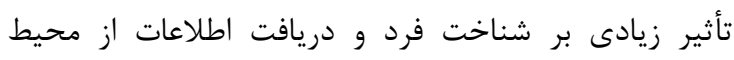

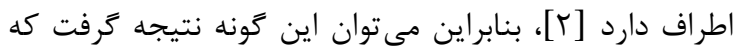

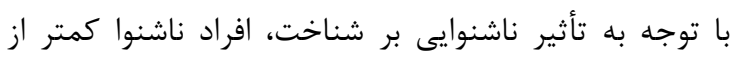

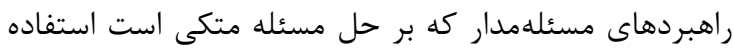


ابراز وجود كند، اين امر زمينههاى بروز يرخاشگرى را در وى

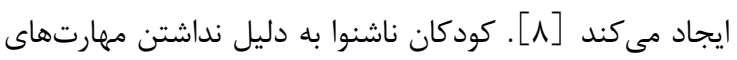

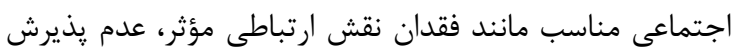

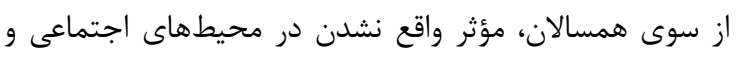

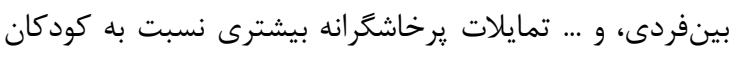

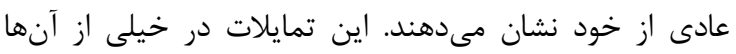

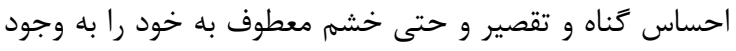

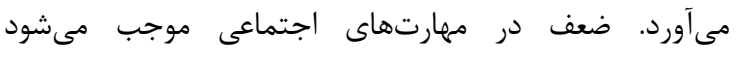

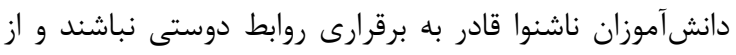

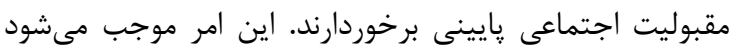

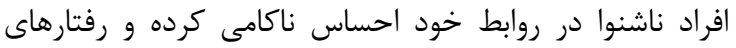

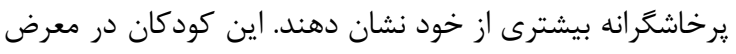

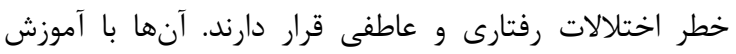

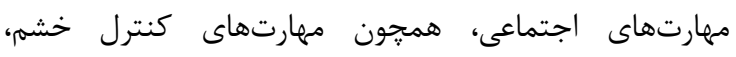

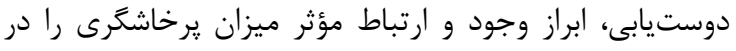

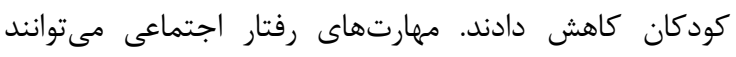

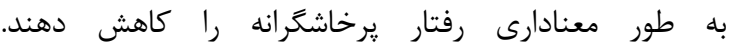

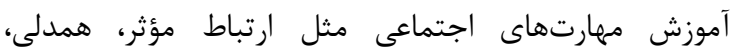

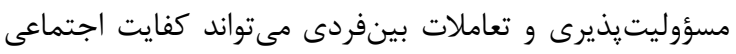

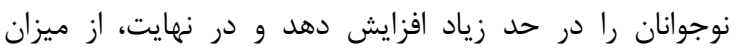

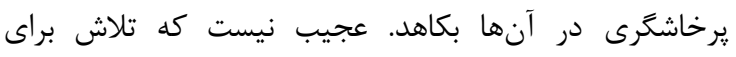
افزايش صلاحيت اجتماعى، مهارتهاى اجتماعى و و كيفيت بهريت

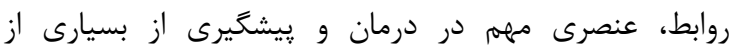

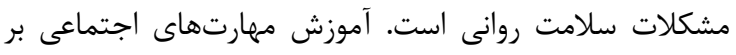

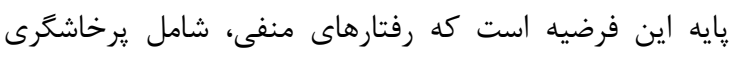
اغلب از كمبود در مهارتهاى مورد نياز براى تعاملات شايسته

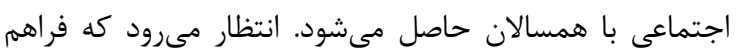

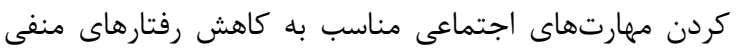

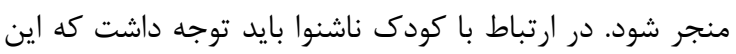

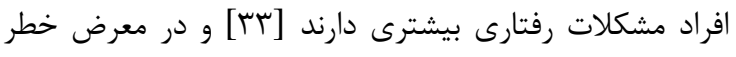

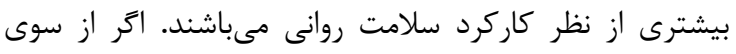

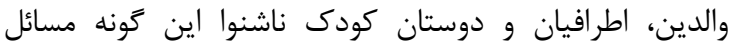

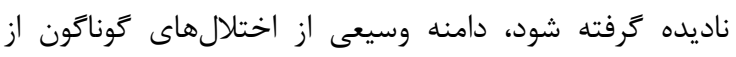

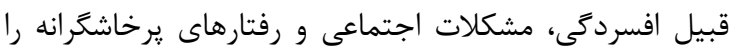

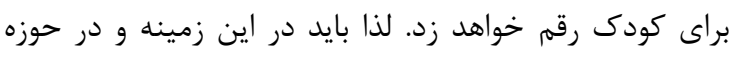

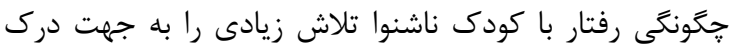
مناسب اين قبيل كودكان انجام داد. روني

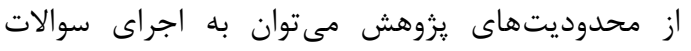

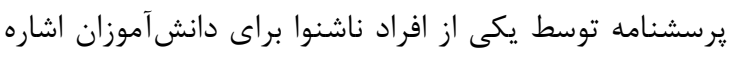
كرد كه اين امر ممكن است در فههم محتواى سوالات خلل ئل

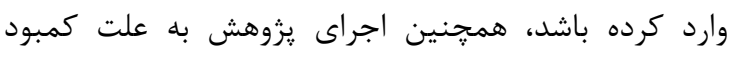

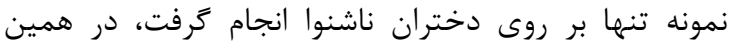

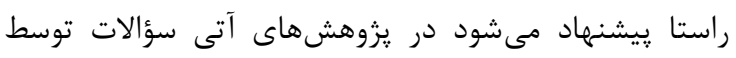
معلمين كه سوكيرى كمتر و توانايى بيشترى در درو توضيح
هيجانى و اجتنابى استفاده كنند ميزان يرخاشگرى بالاتر

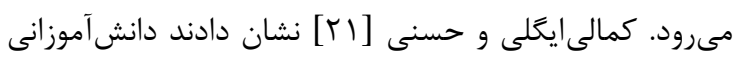
كه از سبك مقابله هيجانمدار و اجتنابى استفاده مي كنئد

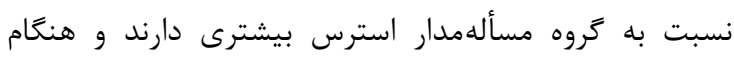

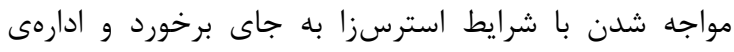

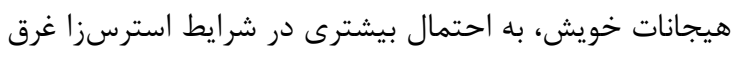

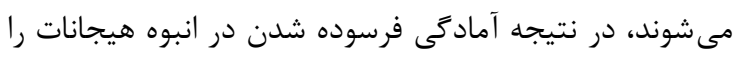

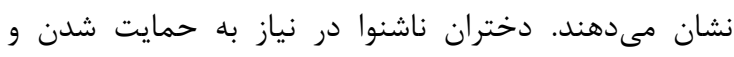

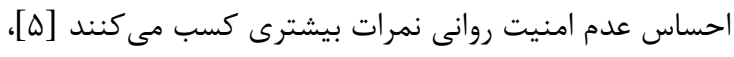

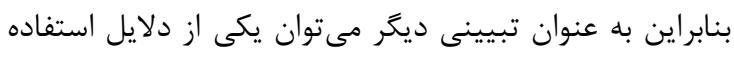

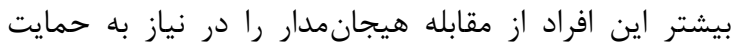

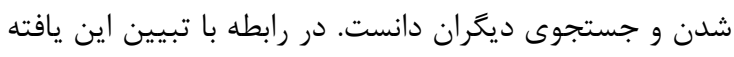

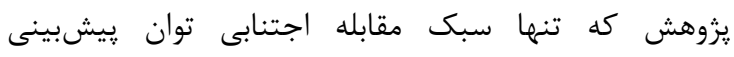

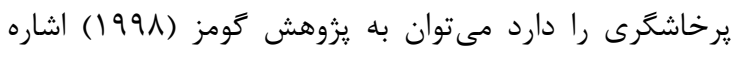

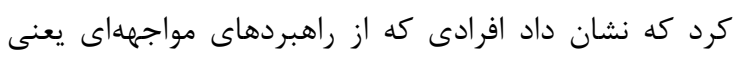

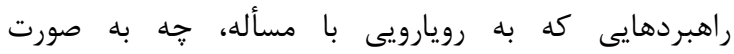
هيجان مدار و جه به صورت مسألهمدار در موقعيتهاي فيه فشارزا

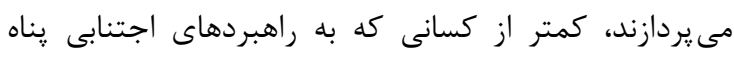

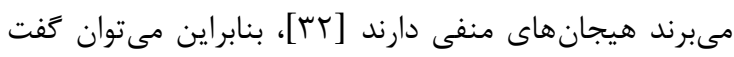

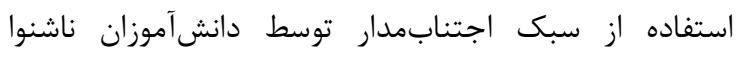

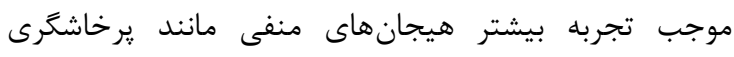
مىشود. نتايج يزوهش همجنين نشان داد بين مهارتهاى اجتماعى

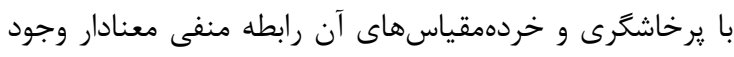

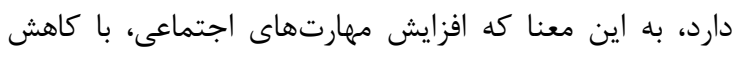

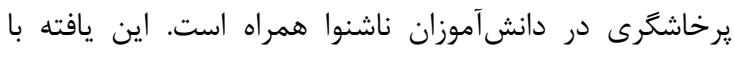

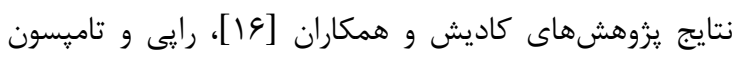

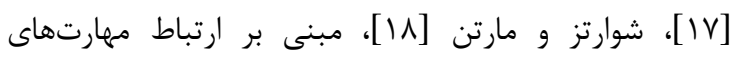

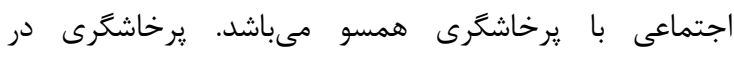

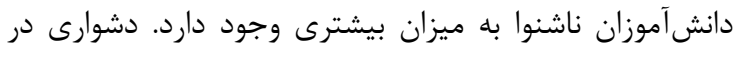

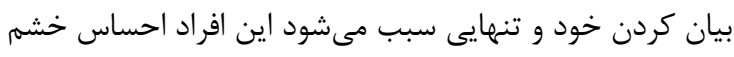
بيشترى كرده و بلصورت يرخاشگرانه رفتار كنند. در محيطهاى

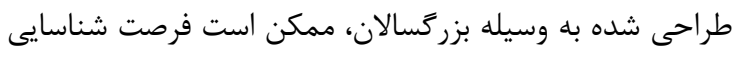

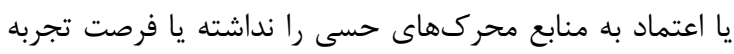

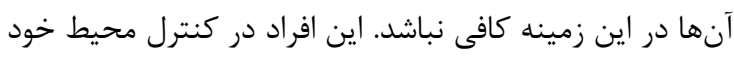

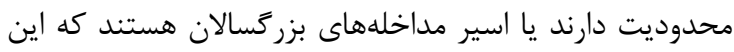

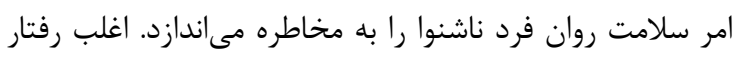

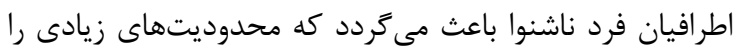

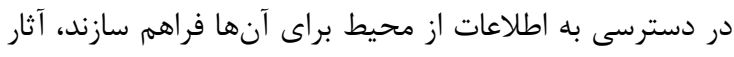

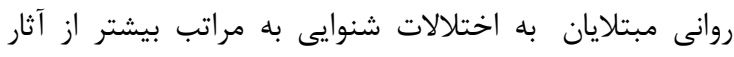

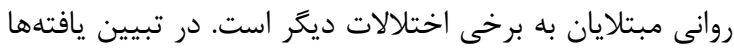

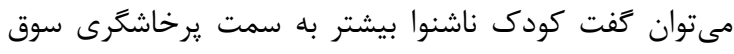

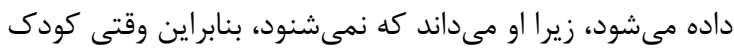

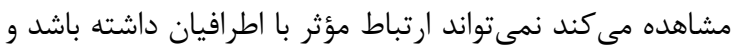




$$
\begin{aligned}
& \text { او نسبت به موقعيت نقش بهسزايى دارد. بنابراين با آموزش افراد } \\
& \text { جهت برخورد مناسب با مشكلات و فشارهاى روانى و استفاده از } \\
& \text { راهبردهاى مناسب مىتوان از ميزان آشفتخى ها، استرس، و در } \\
& \text { نتيجه يرخاشخرى كاست و كمك مؤثرى را جهت بهبود وضعيت } \\
& \text { سلامت روانى آنها به عمل آورد. }
\end{aligned}
$$

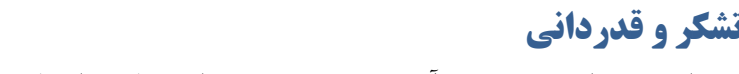

$$
\begin{aligned}
& \text { از مسئولين محترم آموزش و يرورش استثنايى استان } \\
& \text { كرمانشاه، مدارس استثنايى، معلمان و دانشآموزان كه در انجام } \\
& \text { اين يزوهش همكارى داشتند، تشكر مىشود. } \\
& \text { تضاد منافوع } \\
& \text { اين مطالعه براى نويسندگان هيج گَونه تضاد منافعى نداشته } \\
& \text { سؤالات دارند، اجرا شده و نمونهى مورد مطالعه نيز از هر دو }
\end{aligned}
$$

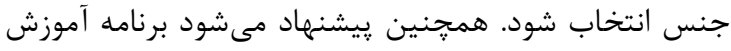

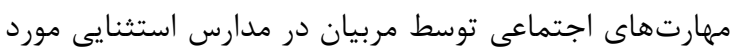

$$
\begin{aligned}
& \text { استفاده قرار زيرد. } \\
& \text { نتيجه تيرى } \\
& \text { نتايج يزوهش حاضر نشان داد بين سبكهاى مقابله با }
\end{aligned}
$$

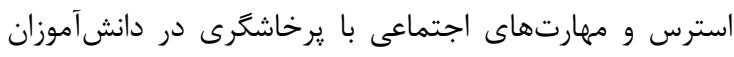

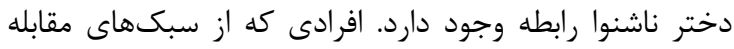

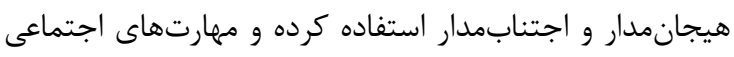

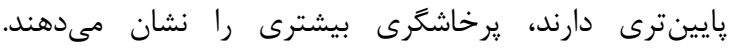

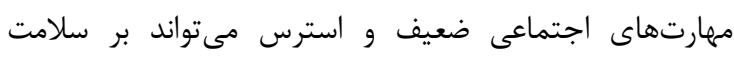

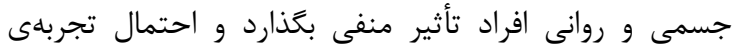

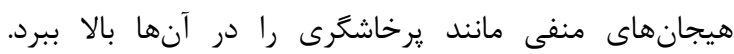

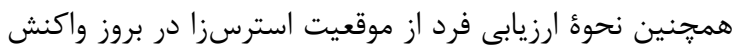

\section{REFERENCES}

1. Foroghmand AM, Galedari H, Mohammadian Gh, Rasekh AA, Ghavabesh J. Distribution patterns of hereditary hearing loss in hearing loss Genetic counseling center in Ahvaz welfare organization. Auditory and vesitibular research, 2011; 20(2), 72-78. (Persian)

2. Milanifar B. Psychology of Exceptional Children. Tehran: Publication Ghomes; 2006. (Persian)

3. Silvester NJ. Mental health and wellbeing: the views of people who are deaf. A thesis submitted to the University of Birmingham for the degree of Doctorate of clinical psychology; 2013.

4. Yuchen M, Tudi J, Chaohe H, Lioing S, Shang D, Binhu $\mathrm{H}$, Huaz H. Genetic Mutations in non syndromic deafness Patients of Uyghur and Han Chinese Ethnicities in Xinjiang China: A Comparative study. Journal of Translational Medicine, 2011; 9, 154. DOI: 10.1186/14795876-9-154

5. Amini D, Afrooz Gh. Sharifi Daramadi P, Homan HA. Recognition of disorders and emotional problems of deaf children using House-Tree-Person and Draw-A-Person tests in comparison with normal children of children of Hamadan province. Scientific Journal of Hamadan University of Medical Sciences. 2013; 20(1): 49-58. (Persian)

6. Burk LR, Armstrong JM, Park J, Zahn-Waxler C, Klein MH, Essex MJ. Stability of early identified aggressive victim status in elementary school and associations with later mental health problems and functional impairments. Abnormal Child Psychology, 2011; 39(2), 225-238. DOI: 10.1007/s10802-010-9454-6

7. Hallahan DP, Kauffman J M, Pullen P. Exceptional learners: Introduction to special education, (11th ed.). Boston: Allyn \& Bacon, 2009.

8. Javanbakhsh F, Motahari nezhad H. Reviews of aggression in deaf children. International Conference on Psychology and cultural life, Istanbul, Mobin Cultural Ambassadors Institute, 2015. (Persian)

9. Babaroglu A. Effect of Hearing Impaired on Children's Aggressive Behavior. International Journal of Psychology and Behavioral Sciences. 2014; 4(5), 179-188. DOI:10.5923/j.ijpbs.20140405.03

10. Van Eldik T, Traffers PD, Veerman JW, Verhulst FC. Mental health problems of deaf Dutch children as indicated by parents' responses to the child behavior checklist. American Annals of the Deaf, 2004; 148(5), 390-395.

11. Sheppard K, Badger T. The lived experience of depression among culturally Deaf adults. Journal of Psychiatric and Mental Health Nursing, 2010; 17(9), 783-789. DOI: 10.1111/j.1365-2850.2010.01606.x.

12. Shahim S. Evaluation of social skills in a group of blind students the teachers. Psychology and Education, 2002; 32 (1), 121-139. (Persian)

13. Moeller MP. Current state of knowledge: psychosocial development in children with hearing impairment. Ear \& Hearing. 2007; 28(6), 729-739. DOI: 10.1097/AUD.0b013e $318157 \mathrm{f} 033$

14. Deluzio J, Girolametto L. Peer interactions of preschool children with and without hearing loss. Journal of Speech, Language, and Hearing Research. 2011; 54(4), 11971210. DOI: 10.1044/1092-4388(2010/10-0099). relationships of deaf children with cochlear implants: predictors of peer entry and peer interaction success. Journal of Deaf Studies and Deaf Education. 2010; 16(1), 108-120. DOI: 10.1093/deafed/enq037 developmental Strengths of Juvenile offerens: Assessing for life Skills. Journal of Addictions and offender counseling. 2001; 21(2), 11-85. DOI: 10.1002/j.2161-1874.2001. tb00154.x

17. Thompson S, Rapee RM. The effect of situational structure on the social performance of socially anxious and non anxious participants, Journal of Behavior Therapy and Experimental Psychiatry, 2002; 33(2), 91-102. http://doi.org/10.1016/S0005-7916(02)00021-6

18. Schwartz RG, Marton K. Articulatory and phonological disorders. 8th ed. Bostone: Allyn \& Bacon, 2010.

19. Steiner H, Erickson JM, Hernandez PL, Pavelski R. Coping styles as correlates of health in high school students. Journal of Adolescent Health, 2002; 30(5), 326- 335. http://doi.org/10.1016/S1054-139X(01)00326-3

20. Halpern LF. The relations of coping and family environment to preschooler's problem behavior. Applied Developmental Psychology, 2004; 25(4), 399- 421. http://doi.org/10.1016/ j.appdev.2004.06.001

21. Kamali Eagle S, Hasani F. The relationship between coping strategies and emotional intelligence and mental health of students participating in the exam classes. Journal of Behavioral Sciences. 2013; 7 (1), 49-56. (Persian)

22. Farzin Rad B, Asgharnejad Farid AA, Yekke yazdandoost R, Habibi Asgarabad M. Comparison of coping strategies and personality styles in depressed and non-depressed students. Journal of Behavioral Sciences, 2010; 4 (1): 17-21. (Persian)

23. Fata L, Motaby F. Kazemzade Atoofi M. Bolhari J. Stress Management: A Guide to Training Workshop. Tehran: Danzheh. 2008; P 12. (Persian)
15. Martin D, Bat-Chaava Y, Lalwami A, Waltzman SB. Peer

16. Kadish TE, Glasser BA, Ginter EJ. Identification The 
24. Beasley M, Thompson T, Davidson J. Resilience in response to life stress: the effects of coping style and cognitive hardiness. Journal of Personality and Individual Differences, 2003; 34(1), 77-95. http://doi.org/10.1016/ S0191-8869(02)00027-2

25. Walker R. Child mental health and deafness. Paediatrics and Child Health, 2013; 23(10), 438-442. http://doi.org/10.1016/ j.paed.2013.06.009

26. Bazzazian S, Besharat MA, Bahrami Ehsan H, Rajab A. Moderating role of coping strategies on the relationship between illness perception and quality of life of glycosylated hemoglobin in patients with diabetes type 1 . Journal of Endocrinology and Metabolism, 2010; 12 (3): 213-221. (Persian)

27. Tangestanizadeh F, Ahmadi AA, Ghoreyshirad FA. Visual comparison of selective attention, working memory, and visual problem solving ability in deaf, hard of hearing, with normal counterparts. MA Thesis. Shahid Madani University of Azerbaijan, Faculty of Psychology and Educational Sciences, 2014. (Persian)

28. Buss AH, Perry M. The Aggression Questionnaire. Journal of Personality and social psychology, 1992; 63(3), 452_459.
PMID: 1403624

29. Samani S. Study of reliability and validity of the Buss and Perry;s Aggression Questionnaire. Iranian Journal of Psychiatry and Clinical Psychology, 2008; 13 (4): 359-365. (Persian)

30. Akbari B, Piri V, Kikhavani S, Piri R. The relationship between coping style and mental health a long with considering the severity of drug addiction in addicted subjects. Scientific Journal of Ilam University of Medical Sciences, 2012; 21(3): 147-154. (Persian)

31. Herbert JD, Forman EM. Acceptance and mindfulness in cognitive behavior therapy: Understanding and applying the new therapies: Wiley, 2011.

32. Elgar J, Arlett C, Groves R. Stress, coping and behavioral problems among rural and urban adolescents. Journal of Adolescents, 2003; 26(5): 574-585. http://doi.org/10.1016/ S0140-1971(03)00057-5

33. Dammeyer J. Psychosocial development in Danish population of children with cochlear implants and deaf and hard-of hearing children. Journal of Deaf Studies and Deaf Education. 2010; 15(1), 50-58. https://doi.org/10.1093/ deafed/enp024 